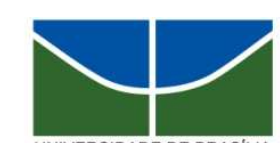

UNIVERSIDADE DE BRASÍLIA

Centro de Excelência em Turismo

Pós-graduação Lato Sensu

Curso de Especialização em Qualidade em Alimentos

\title{
PESQUISA SOBRE A TÉCNICA DE SOUS VIDE
}

Dalila Loreny Medeiros

Prof. Dra. Rita Akutsu

Brasília - 2009 


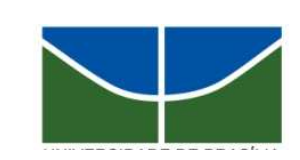

UNIVERSIDADE DE BRASÍLIA

Centro de Excelência em Turismo

Pós-graduação Lato Sensu

Curso de Especialização em Qualidade em Alimentos

\section{PESQUISA SOBRE A TÉCNICA DE SOUS VIDE}

Dalila Loreny Medeiros

Prof. Dra. Rita Akutsu

Monografia apresentada ao Centro de Excelência em Turismo - CET, da Universidade de Brasília UnB, como requisito parcial à obtenção do grau de Especialista em Qualidade em Alimentos.

Brasília - 2009 
Medeiros, Dalila.

Pesquisa sobre a técnica de sous vide / Dalila

Medeiros. - Brasília, 2009.

xvi, ...f. : il.

Monografia (especialização) - Universidade de Brasília, Centro de Excelência em Turismo, 2009.

Orientador: Rita Akutsu. 
UNIVERSIDADE DE BRASÍLIA

Centro de Excelência em Turismo

Pós-graduação Lato Sensu

Curso de Especialização em Qualidade em Alimentos

Dalila Loreny Medeiros

Aprovado por:

Orientador: Dra Rita de Cássia Coelho de Almeida Akutsu

Prof_. $_{\text {a }}{ }^{\mathrm{a}}$. Karin Eleonora Sávio de Oliveira

Proff. MSc Lívia de Lacerda de Oliveira Pineli

Brasília, 14 de maio de 2009. 
Dedico esta monografia ao Dr. Eneo da Silva Júnior, que incentivou e acreditou na realização deste trabalho. 


\section{AGRADECIMENTOS}

A equipe do I Maestri, principalmente ao Chef Rodrigo Sanchez por permitir a realização deste trabalho em seu restaurante, bem como seu acompanhamento e explicações.

A professora Rita Akutsu por todas as orientações, dedicação, compreensão e atenção dispensada para a realização deste trabalho.

Ao Jerrand, por sua importante contribuição com os artigos e livros estrangeiros.

A minha querida mãe e ao meu namorado Fabrício por compreenderem minha ausência e me incentivarem a prosseguir. 
"Na ocorrência da vida, são muitos os contratempos. As bactérias, os vírus e os fungos são apenas uma lembrança de que os erros e os descuidos estão dentro de nós mesmos"

Dr. Eneo Alves da Silva Júnior, 2007. 


\section{RESUMO}

O objetivo deste trabalho foi pesquisar a técnica de sous vide e acompanhar a técnica aplicada na produção de alimentos no restaurante flutuante na cidade de Brasília - DF. O desenho é de um estudo de caso realizado entre o mês de outubro e novembro de 2008. O acompanhamento da técnica recebeu suporte fotográfico além do preenchimento de ficha técnica, cálculo do valor nutricional da preparação com base nos valores da tabela TACO e especificação do equipamento utilizado como inovação, em paralelo fez-se pesquisa bibliográfica da técnica e de seus procedimentos verificando sua versatilidade e coerência com a realizada no restaurante escolhido para o presente estudo. Sous-vide é uma técnica que engloba diversas vantagens econômicas, gastronômicas e nutricionais, mas para que se chegue a estes resultados, cuidados com mão de obra qualificada, boas práticas, tempo/temperatura e HACCP devem ser constantes. Conclui-se que apesar de ser uma técnica que surgiu a cinco décadas atrás, pesquisas exploratórias precisam ser realizadas para que se tenha uma maior compreensão da técnica bem como suas inovações, segurança microbiológica e preservação nutricional da matéria prima utilizada. Ainda, finalizo com a constatação da necessidade de reciclagem de boas práticas de manipulação e de mão de obra qualificada evidenciada durante o acompanhamento da técnica no restaurante flutuante. 


\begin{abstract}
The objective of this study was to investigate the technique of sous vide and monitor the technology used in food production in the floating restaurant in the city of Brasilia - DF. The design is a case study conducted between October and November 2008. The Monitoring of the technic included photographic support and the completion of a technical sheet. The nutritional value of the preparation was calculated based on the values of the TACO table and the specification of the innovative equipment used. In parallel a Bibliographic, procedure and technical research has been made in order to verify the versatility and consistency of the sous vide cooking method used in the restaurant chosen for this study. Sous-vide is a technique that incorporates several economic, gastronomic and nutrition advantages, but to reach these results, care for highly-qualified labor, best practices, time/temperature and HACCP should be constantly used. It is concluded that despite being a technique that came to life five decades ago, exploratory research should be conducted to have a greater understanding of technic and its innovations, microbiological safety and the preservation of nutritional raw aterials used. Still, i conclude with the need for recycling of the qualified workers that participated in this study, evidence in the technical monitoring of the floating restaurant showed that this recycling has to be done more often when using the sous vide cooking technic.
\end{abstract}




\section{LISTA DE FIGURAS}

Figura 1. Diagrama do sistema de produção AGS............................................................16

Figura 2. Fluxograma da técnica de sous-vide realizada no restaurante flutuante...................28

Figura 3. Utilização do tambler na técnica de sous-vide .....................................................29

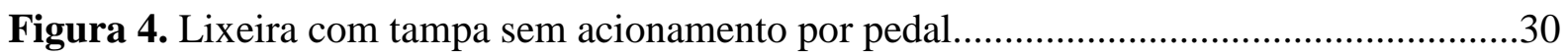

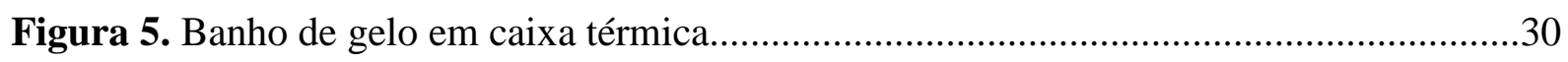

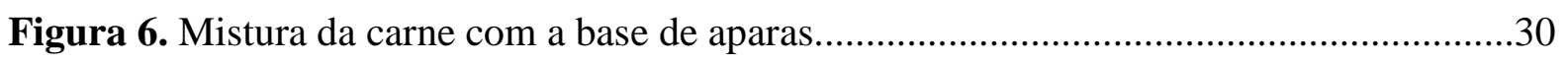




\section{ABREVIATURAS}

OMS = Organização Mundial da Saúde

AGS = iniciais dos nomes dos três hospitais pioneiros da técnica de sous-vide: Anderson Area Medical Center, Greenville Memorial Hospital, Spartanburg Regional Hospital System UAN = Unidade de Alimentação e Nutrição aw $=$ atividade de água 


\section{SUMÁRIO}

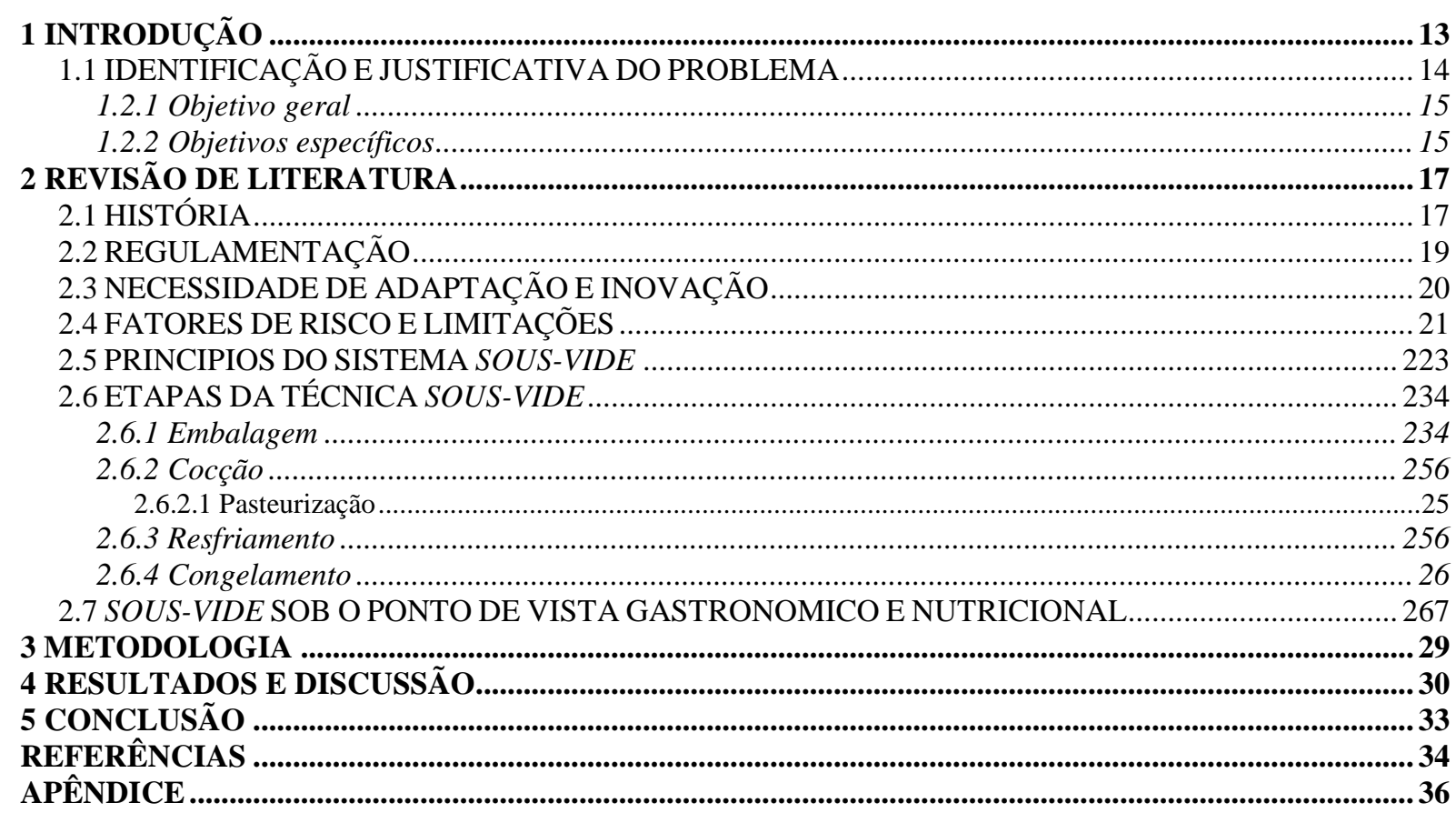




\section{INTRODUÇÃO}

Sous-vide ${ }^{1}$, refere-se a um método de cozinhar alimentos crus em embalagens plásticas apropriadas seladas à vácuo em baixas temperaturas por um longo período de tempo, após o término do cozimento o alimento pode ser armazenado ou complementado com algum outro ingrediente que compõe a receita e consumido. (TANSEY; GORMLEY, 2004).

O processo de sous-vide é baseado em três princípios:

a) Uso de embalagem plástica laminada resistente a temperatura para prevenir a recontaminação e perda de substâncias constitutivas do alimento;

b) Uso do vácuo para remover o ar e evitar a oxidação do alimento;

c) Uso de um processo de cozimento a baixa temperatura (TANSEY; GORMLEY, 2004).

O vácuo da embalagem evita a degradação do alimento por microorganismos aeróbios, bem como a rancidez provocada por oxidação lipídica, processos responsáveis pela alteração de sabor durante o armazenamento refrigerado seguido de cocção de alimentos embalados na presença de oxigênio. Torna-se relevante ao se pensar em produtos cárneos que pode ter seu sabor natural completamente alterado limitando sua aceitabilidade quando proveniente do sistema de embalagem e cozimento convencional (VAUDAGNA, et al. 2002b).

O processo de manter um alimento sob vácuo permite a preservação dos aspectos naturais do alimento, tais como: frescor, cor, sabor, teor nutricional, umidade e a aparência desde o pré-preparo até seu consumo. Contudo, é preciso cautela no consumo de alimentos manipulados com a técnica de sous-vide, devido ao perigo de saúde pública que existe na utilização da técnica de forma negligente, que possa resultar em diversas doenças de origem alimentar (VAUDAGNA, et al. 2002b).

Segundo a Organização Mundial de Saúde (2008), doença que é transmitida por alimento possui natureza infecciosa ou tóxica causada por agentes que entram no organismo por meio da ingestão de alimento ou de água. É um dos principais problemas de saúde

\footnotetext{
${ }^{1}$ Sous-vide, que em francês, que dizer "sob vácuo" (TANSEY; GORMLEY, 2004).
} 
mundial e tem um considerável impacto socioeconômico em consequiência da redução da atividade produtiva por incapacitação das pessoas de dar continuidade ao trabalho, mesmo que na fase de recuperação.

Os riscos podem ser prevenidos se levar em consideração aspectos de segurança e higiene alimentar desde a aquisição da matéria prima, manipulação adequada e controle de tempo/temperatura em todos os passos do procedimento. A pasteurização se torna uma aliada no combate a contaminação, além de ser a fase essencial que define a qualidade sensorial e validade dos produtos sous-vide.

Um dos fatores que interferem diretamente na veiculação de doenças transmitidas por alimentos é a falta de preparo e os erros cometidos nos programas de treinamento dos manipuladores de alimentos, donas de casa e consumidores ocasionando falhas nas boas práticas de manipulação dos alimentos (RESENDE, 1993; PANETTA, 2001).

No entanto, é de suma importância o treinamento constante da equipe de produção de alimentos por pessoas capacitadas a ministrar tais treinamentos, para que os manipuladores de alimentos tenham consciência da seriedade que é manipular um alimento e da importância da utilização das boas práticas de manipulação e seguimento dos procedimentos operacionais padrões, estabelecidos juntamente com as normas da empresa com embasamento teórico e em legislações vigente (SILVA JUNIOR, 2007).

\subsection{IDENTIFICAÇÃO E JUSTIFICATIVA DO PROBLEMA}

As grandes modificações e melhorias que ocorreram nas últimas décadas, referente à técnica de sous-vide, também conhecida como "bolsa de cozinhar", devem-se as empresas que preparam alimentos bem como as unidades de transformações que buscam minimizar perdas e preservar a qualidade sensorial do alimento além de prolongar sua vida útil (VAUDAGNA, et al. 2002a). Com a globalização, e o aprimoramento dos procedimentos de cozinhar a técnica de sous-vide começa a se tornar mais popular no preparo de pratos gourmet, bem como no mercado consumidor que procura pelo consumo de alimentos não só saborosos, mas que agrega qualidade nutricional (GARCÍA-LINARES, et al.2004).

Para realização da técnica de sous-vide são necessários equipamentos específicos com custo relativamente alto, tais como embalagens específicas para vácuo, máquina para embalar, banho-maria, termômetro de espeto, resfriador. A necessidade destes itens dificulta a 
efetivação da técnica em residências, sendo viável apenas para restaurantes e indústrias de alimentos.

A realização deste estudo surgiu com a necessidade de compreensão da técnica, identificação e correção dos erros verificados durante o acompanhamento dos procedimentos do sous-vide, englobando uma técnica pouco conhecida pelos próprios manipuladores de alimentos que a utilizam em meu ambiente de trabalho, reafirmando a necessidade de treinamento e especialização de mão de obra para a realização de todo procedimento de forma segura.

Este trabalho é fundamental para o conhecimento da técnica, aplicação correta dos procedimentos, elaboração e aplicação de treinamento adequado e específico para os manipuladores e para que a Empresa que utiliza essa técnica, a qual permitiu a realização do estudo, não seja mais uma a utilizar a técnica de sous-vide de forma indiscriminada colocando em risco a saúde e o bem estar de seus clientes.

\subsection{OBJETIVOS}

\subsubsection{Objetivo geral}

O objetivo deste trabalho é conhecer a técnica de sous-vide com acompanhamento do procedimento aplicado na produção de alguns alimentos da empresa em que trabalho.

\subsubsection{Objetivos específicos}

- Revisar o surgimento da técnica de sous- vide

- Pesquisar o procedimento tradicional da técnica

- Identificar as vantagens e as desvantagens do sous-vide

- Elucidar a contribuição do sous-vide para a gastronomia e a nutrição

- Explorar a técnica de sous-vide realizada no restaurante flutuante, ancorado em um hotel em Brasília, e seus possíveis erros de manipulação 


\section{REVISÃO DE LITERATURA}

\subsection{HISTÓRIA}

Apesar de ainda pouco conhecida no mundo, o cozimento do alimento a vácuo em embalagem selada não é uma técnica nova. No passado uma bexiga de porco foi utilizada para envolver o alimento (em formato papillote) antes de cozinhar, e este método foi precursor do sistema sous-vide (TANSEY; GORMLEY, 2004).

O primeiro uso do cozimento a vácuo de alimentos em larga escala foi nas companhias de Catering no final da década de 1960 com o desenvolvimento do sistema Nacka que originou-se na Suécia, usando a tecnologia de embalar um produto aquecido a $80^{\circ} \mathrm{C}$ em sacolas plásticas vedadas a vácuo, seguidas de pasteurização por ebulição a $100^{\circ} \mathrm{C}$ por 3 minutos. Posteriormente refrigerado em água a $4^{\circ} \mathrm{C}$ e armazenado em refrigeração controlada, com vida útil de 2 a 21 dias. A finalização do alimento ocorre com aquecimento a $80^{\circ} \mathrm{C}$ antes do consumo (TANSEY; GORMLEY, 2004).

Posteiormente surge o aperfeiçoamento do sistema Nacka, testado nos hospitais Anderson Area Medical Center, Greenville Memorial Hospital, Spartanburg Regional Hospital System denominado sistema AGS ${ }^{2}$ (FARBER, 1995).

O sistema AGS inclui a embalagem a vácuo dos alimentos crus ou parcialmente cozidos em bolsas plásticas, seguidos de pasteurização e resfriamento em água a temperatura de $2^{\circ} \mathrm{C}$ e armazenamento a temperatura entre 0 e $2^{\circ} \mathrm{C}$ por no máximo 60 dias. Sua finalização precede o aquecimento a temperatura de $70^{\circ} \mathrm{C}$ no ponto geométrico do alimentos antes do consumo (TANSEY; GORMLEY, 2004).

Mesmo sendo uma técnica desenvolvida em 1960, o sistema AGS continua sendo utilizado nos dias atuais, recebendo denominação de sous-vide e com a inclusão de novos equipamentos e aplicação em novos alimentos, sem perder é claro a essência da técnica que consiste em cozinhar o alimento à vácuo.

\footnotetext{
2 AGS sigla composta pelas iniciais dos nomes dos três hospitais pioneiros da técnica: Anderson Area Medical Center, Greenville Memorial Hospital, Spartanburg Regional Hospital System
} 
Sous-vide é o nome dado ao processo de cocção desenvolvido pelo chef francês George Pralus em 1974, sua tradução denota "sob vácuo", cuja técnica já era realizada desde a década passada como visto do sistema AGS. Pralus trabalhava em um restaurante Francês, que apresentava uma perda significativa na cocção do foie gras $^{3}$ popularmente conhecido como patê de fígado de ganso, após inúmeras tentativas conseguiu reduzir a perda de $40 \%$ para 5\% além de preservar o sabor e o valor nutricional da preparação. Após essa descoberta, inúmeras receitas com carnes, legumes, frutas, foram criadas utilizando como procedimento culinário, a técnica de sous-vide (CAMPOS, 2008).

Outra opção é a realização da técnica de sous-vide para consumo futuro, ou seja, após o período de cocção as bolsas plásticas sofrem um resfriamento rápido para paralisar o cozimento, são armazenadas sob refrigeração ou congelamento, contudo sua vida útil vai depender, dentre outros fatores, da temperatura em que se encontra armazenado (TANSEY; GORMLEY, 2004).

O fluxograma abaixo ilustra o sistema AGS de produção básico, que pode ser modificado de acordo com a realidade da unidade que estiver realizando a técnica.

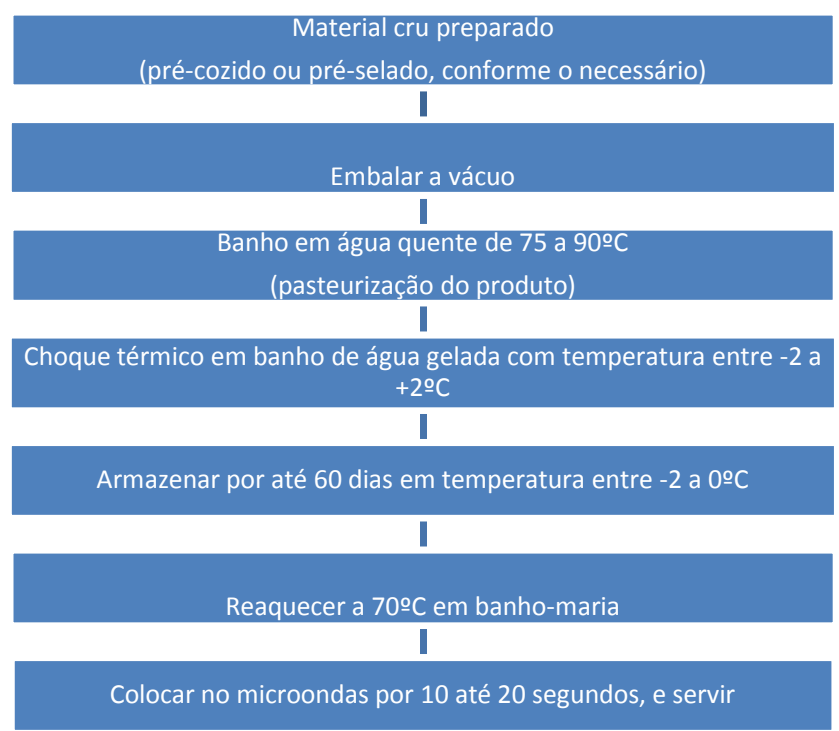

Fig. 1. Diagrama do sistema de produção AGS

Fonte: Adaptado de LIGHT, 1990, p. 151.

\footnotetext{
${ }^{3}$ Foie gras nome francês que significa "fígado gordo", por ser retirado de patos ou gansos super alimentados (CAMPOS, 2008).
} 
No fluxograma do sistema AGS, tem-se a utilização do equipamento microondas antes de servir o alimento, já na técnica de sous-vide a finalização do alimento vai depender da aparência final que o chef quer dar ao seu prato, seja ela com o auxílio de um maçarico, ou uma frigideira bem quente ou até mesmo o microondas. A técnica de sous-vide traz a liberdade de criação e ousadia para a culinária, principalmente da alta gastronomia (CAMPOS, 2008).

\subsection{REGULAMENTAÇÃO}

Apesar de ser uma técnica do século passado, alguns países não possuem regulamentação específica e os processos que integram a técnica de sous-vide seguem normas inseridas no Código Alimentar Americano (Food Code - USA), esse código de boas práticas publicado pela FDA (Food and Drug Administration) abrange instruções no sentido de prevenir a ocorrência de doenças de origem alimentar. já diversos países da Europa seguem a norma do departamento de saúde da Inglaterra (PERLIK, 2006).

A prática indiscriminada da técnica pode ocasionar em uma bolsa de bactérias, contudo, esse procedimento exige familiaridade do assunto para o manipulador que realizará o processo, seguindo as práticas de manuseio de alimentos seguros. Não foi por acaso que, em março de 2006 na cidade de Nova York, o Departamento de Saúde e Higiene visualizando potenciais efeitos mortais da realização indevida da embalagem a vácuo proibiu a técnica de sous vide em restaurantes, que não possuíam aprovação do sistema APPCC (Análise dos Perigos e Pontos Críticos de Controle), além de restrições específicas para os diversos tipos de alimentos (PERLIK, 2006).

No Brasil não existe uma regulamentação específica para a técnica de sous-vide, entretanto, existem legislações vigentes para a produção de alimentos que não devem ser transgredidas nos procedimentos de manipulação bem como na técnica de sous-vide, dentre essas legislações podemos citar em especial a Portaria CVS 6/99 e a Resolução RDC 216/04, que estabelecem critérios de tempo e temperatura para as etapas de produção de refeições, desde o recebimento, manipulação, distribuição e armazenamento (KAWASAKI, 2007). 


\subsection{NECESSIDADE DE ADAPTAÇÃO E INOVAÇÃO}

No sistema de produção de alimentos existente no Brasil desde a década de 1960 e 1970 predominou o procedimento de manipulação próximo ao horário de servir, sendo os alimentos conservados em equipamentos térmicos ou refrigerados, servidos aos consumidores no mesmo local de produção. Já na década de 1980, com o aumento da competitividade entre as unidades produtoras, surge a necessidade de minimizar desperdícios e a instalação do sistema de produção centralizado, caracterizado por uma produção de alimentos em uma cozinha, seguido de transporte para demais cozinhas satélites apenas para serem finalizados e servidos (KAWASAKI, 2007).

Diversas vantagens são vistas no sistema de produção centralizado, que incorpora a técnica de sous-vide, dentre elas: economia de escala possibilitando a aquisição de matériaprima em condições vantajosas, aumento do controle de recebimento, armazenamento e produção, otimização da utilização de equipamentos, área física e tempo de mão-de-obra em função das quantidades produzidas, concentração de manipulador habilitado na cozinha central (KELLER, 2008).

O procedimento aprimorado por George Pralus e denominado de sous-vide, permite cozinhar carnes macias, carnes fibrosas (mais duras), peixes, frutos do mar, vegetais e raízes como a batata e a mandioca, além da realização de processos de marinar, compressar e modelar os alimentos (KELLER, 2008). A microbiologia da matéria-prima utilizada no sousvide é determinante para a segurança no consumo do alimento, que pode ser controlada pela intensidade e duração do tratamento térmico, temperatura alcançada pela rapidez do resfriamento e controle de armazenamento refrigerado ou congelado (GARCÍA-LINARES et al., 2004).

A tecnologia de cozinhar alimentos embalados à vácuo engloba os sistemas cookchill e cook-freeze em seus procedimentos, sendo que o sistema de produção de cocção de alimentos cook-chill é caracterizado pela preparação e cocção tradicional dos alimentos seguido de porcionamento, refrigeração em condições controladas de temperatura e armazenamento sob refrigeração com reaquecimento antes de servir o alimento. O sistema cook-freeze é similar ao sistema cook-chill, e seu diferencial é o congelamento do alimento a temperatura de $-18^{\circ} \mathrm{C}$ e possível armazenamento por um período de até 6 meses (KINTON et al. 1998). 
O sistema cook-freeze quando realizado separadamente da técnica de sous-vide, é utilizado em menor escala que o cook-chill devido ao alto consumo de energia e também pelo fato de muitos alimentos sofrer alterações em suas características sensoriais após um período de congelamento (KAWASAKI, 2007).

\subsection{FATORES DE RISCO E LIMITAÇÕES}

Diversos fatores podem influenciar a segurança microbiológica do alimento utilizado na técnica de sous-vide desde que não seja feito um controle higiênico sanitário de todas as etapas, dentre estes fatores podemos citar: seu cultivo, transporte, armazenamento antes e após sua aquisição, forma de manipulação, ambiente, móveis e utensílios para a realização dos procedimentos, e a própria natureza do alimento $(\mathrm{pH}$, atividade de água, teor de gordura, aminoácidos e enzimas). Estes fatores também determinam a eficácia do tratamento térmico e a possível proliferação de patógenos (GARCÍA-LINARES, et al. 2004).

Potenciais riscos microbiológicos podem estar presentes na matéria-prima ou serem veiculados durante a manipulação, que em técnicas convencionais de processamento de alimentos poderiam ser eliminados por congelamento ou calor intenso, mas na técnica de embalar a vácuo, esses microorganismos podem proliferar, (SHELDON MARGEN; OGAR, 1989) estando associados em quatro categorias:

- Termoestáveis Produtores de toxinas como: Staphylococcus aureus (temperatura ótima de $37^{\circ} \mathrm{C}, \mathrm{pH} 7$ e aw 0,83 ) e Bacillus cereus (temperatura ótima de $30^{\circ} \mathrm{C}, \mathrm{pH} 7$ e aw 0,93);

- Anaeróbios facultativos como: Yersinia enterocolítica (temperatura ótima de $30^{\circ} \mathrm{C}, \mathrm{pH}$ 7 e aw 0,97), Listéria monocytogenes (temperatura ótima de $37^{\circ} \mathrm{C}, \mathrm{pH} 7$ );

- Formadores de esporos e de agentes patogênicos como: Clostridium botulinum tipo E (temperatura ótima de $30^{\circ} \mathrm{C}, \mathrm{pH} 7$ e aw 0,97 ). $\mathrm{Na}$ forma de esporos, mais preocupante por ser mais resistente ao calor;

- Organismos mesófilos como Botulinum C, Clostridium perfringens (temperatura ótima de $37^{\circ} \mathrm{C}, \mathrm{pH} 7$ ), Salmonella ssp. (temperatura ótima de $43^{\circ} \mathrm{C}, \mathrm{pH} 7$ e aw 0,95 ), Escherichia coli e S. aureus são pouco preocupantes nos alimentos armazenados em condições adequadas de temperatura $\left(<5^{\circ} \mathrm{C}\right)$, contudo esses organismos podem ser motivo de interesse para os alimentos armazenados / distribuídos em temperatura inadequada, acima de $10^{\circ} \mathrm{C}$ (VAUDAGNA, et al. 2007). 
$\mathrm{Na}$ busca de produzir um alimento seguro em meio a tantos microorganismos causadores de doenças de origem alimentar, unidades que utilizam a técnica de sous-vide buscam na temperatura um meio de eliminar os microorganismos que julgam prejudiciais, porém, o tratamento térmico realizado com o processo de pasteurização não é suficiente para dizer que tal alimento está livre de contaminação, ou seja, este processo elimina os organismos patogênicos, entretanto pode-se dizer que um alimento pasteurizado está seguro para consumo, diferentemente do processo de esterilização realizado com temperaturas elevadas (procedimento utilizado em conservas) por tempo suficiente para extinguir todo e qualquer microorganismo presente no alimento (VYNCKT, 1990).

Existem contratempos não só referente ao aspecto microbiológico, mas também sensorial, ou seja, algumas preparações não se adéquam a técnica de sous-vide. Como preparações grelhadas, hortaliças refogados e frituras, por perderem a textura crocante ou a maciez, e produtos de panificação que podem perder seu formato e textura com a pressão exercida no momento da remoção do oxigênio da embalagem. Além da alteração na coloração dos vegetais verdes, os grãos e cereais também não recebem benefícios apreciáveis com a técnica de cozimento a vácuo (KELLER, 2008). Portanto, as preparações que utilizam alimentos cozidos são as melhores para utilização do procedimento de cozinhar em embalagens à vácuo.

O procedimento de embalar um alimento a vácuo pode prolongar sua vida de prateleira, por eliminar o oxigênio que favorece a deterioração oxidativa de alimentos que sustenta a vida e o crescimento de microorganismos aeróbios. Alimentos cárneos são também favorecidos nas preparações que utilizam o sous-vide, pois a ausência de oxigênio diminui a velocidade das reações que causam a rancidez oxidativa por seu elevado teor de gordura e contato com o oxigênio.

A deteriorização ocasionada por organismos aeróbios e anaeróbios, bem como suas alterações de cor, odor e sabor podem ser positivas para alertar o consumidor, pois este poderá identificar que o produto encontra-se impróprio para consumo ao observar alterações visíveis do produto em decorrência de falha em alguma etapa do processamento do alimento (VAUDAGNA et al., 2002b).

Os organismos anaeróbias demandam um meio ambiente livre de oxigênio para seu desenvolvimento normal. Anaeróbios estritos podem ser mortos na presença de oxigênio e não fazem uso de oxigênio para produção de energia. Existe uma grande variedade de níveis de tolerância ao oxigênio entre os microrganismos anaeróbios. O Clostridium, é um 
microorganismo anaeróbio de relevância médica devido a sua resposta a infecção clinica (VAUDAGNA et al., 2002b).

A degradação lipídica resulta em alterações de cheiro e sabor, popularmente conhecida como rancidez ou ranço, e essas alterações diminuem o prazo de validade do produto além de torná-lo inconsumível, porém, a utilização da técnica de sous-vide pode adiar esses processos (FARBER; DODDS, 2008).

A rancidez pode ser oxidativa ou hidrolítica, a primeira envolve a divisão de ácidos graxos insaturados por meio de radicais livres, que tem como resultado a formação de aldeídos, cetonas e ácidos graxos de cadeia curta. Os radicais livres e os peróxidos formados durante a oxidação lipídica pode também alterar a pigmentação dos alimentos, destruir as vitaminas A e E, hidrolisar proteínas e causar o escurecimento da gordura presente neste alimento. Outro fator que pode influenciar na taxa de rancidez é a atividade de água, ou seja, quanto mais baixa a atividade de água $(<0,3)$ mais rápido ocorrerá o processo de rancidez oxidativa, estes acontecimentos podem ser potencializados na técnica de sous-vide se realizada de forma incorreta (FARBER; DODDS, 2008).

Em contrapartida, a rancidez hidrolítica ocorre na ausência de oxigênio, resultante da hidrólise de triglicerídeos e liberação de glicerol e ácidos graxos. Esse tipo de oxidação pode ser aumentado pela presença de umidade e de enzimas endógenas, tal como lípases. As lipoxigenases catalisam a oxidação de gorduras insaturadas, bem como compostos orgânicos voláteis, que são estáveis ao calor e pode sobreviver a processos de pré-cozinhar e assar. Sendo esse processo um dos mais preocupantes da técnica de cozinhar alimentos embalados à vácuo, pois todo seu procedimento favorece a rancidez hidrolítica (FARBER; DODDS, 2008).

Afim, de minimizar e controlar todos os riscos citados anteriormente, levando em consideração as limitações, o principio da técnica de sous-vide deve ser mantido principalmente se tratando do controle de tempo e temperatura das etapas que constituem este sistema.

\subsection{PRINCIPIOS DO SISTEMA SOUS-VIDE}

Os princípios a seguir são genéricos, e devem ser realizados com cautela pois o binômio tempo/temperatura dependerá do alimento utilizado, bem como da legislação em vigor. 
- Utilizar matéria-prima de boa qualidade microbiológica, com procedência conhecida, recebida e armazenada em condições adequadas conforme legislação vigente;

- Cozer os alimentos em temperatura que destrua as células vegetativas dos microorganismos patogênicos, de forma que o centro do alimento atinja temperatura de $74^{\circ} \mathrm{C}$

- Resfriar rapidamente os alimentos a temperatura de pelo menos $3^{\circ} \mathrm{C}$ em 90 minutos, logo após o cozimento para controlar a multiplicação dos microorganismos que possam ter sobrevivido a cocção;

- Armazenar os alimentos em temperaturas entre $0^{\circ} \mathrm{C}$ e $3^{\circ} \mathrm{C}$ por no máximo 5 dias, incluindo o dia da produção e o dia do consumo;

- Reaquecer os alimentos a temperatura de $70^{\circ} \mathrm{C}$ no seu centro geométrico por 2 minutos;

- Distribuir a temperaturas superiores a $63^{\circ} \mathrm{C}$ quando forem consumidos quentes e abaixo de $3^{\circ} \mathrm{C}$ quando consumidos frios (KAWASAKI, 2007).

Além das recomendações das Boas Práticas de Fabricação durante todo o processo de produção, a adoção do método APPCC é fundamental para garantia da inocuidade dos alimentos submetidos à técnica de sous-vide (KAWASAKI, 2007).

\subsection{ETAPAS DA TÉCNICA SOUS-VIDE}

\subsubsection{Embalagem}

Antes de embalar os alimentos é necessário realizar os procedimentos de higienização, tempero e porcionamento específico para cada alimento. Posteriormente deve-se analisar o alimento a ser embalado e a pressão de vácuo a ser estipulada, pois esta pode causar danos futuros ao produto, ou seja, o alimento pode ser delicado e ser esmagado com a pressão, ou ter partes pontiagudas que podem perfurar a embalagem. Já para alimentos duros como a cenoura e algumas carnes é necessária alta pressão para que todo o oxigênio seja removido e a embalagem fique completamente aderida com a maior área de contato possível (KELLER, 2008).

Existem regulamentações técnicas para a produção destas embalagens para vácuo, ainda, a certificação AUP, Autorização de Uso de Produto que o Ministério da Agricultura e 
do Abastecimento concede às empresas fabricantes, certificando que a empresa está apta a produzir e comercializar embalagens. As embalagens empregadas nesse sistema podem utilizar dois tipos de filmes: os termoencolhíveis, que possuem basicamente PVdc (cloreto de polivinilideno) em sua composição e os não-termoencolhíeis, que possuem PA (poliamida) (VAUDAGNA et al., 2002a).

Algumas observações são importantes no momento de embalar um alimento à vácuo, através de observação visual verificar se o plástico esta bem aderido ao alimento. Caso não esteja, isso indica que a embalagem não está bem vedada. Para embalar a vácuo há necessidade de uma máquina que forneça o vácuo e sele, e também embalagens próprias para vácuo (VAUDAGNA et al., 2002b).

Equipamentos específicos são necessários para utilizar embalagens à vácuo, como as máquinas seladoras com sistema de câmara e bomba de sucção de ar. Estas máquinas geralmente possuem câmaras de sucção e estrutura em aço inox, tampa de acrílico transparente e bomba de sucção que permite de 2 a 4 ciclos p/minuto (VAUDAGNA et al., 2002b). Estes equipamentos estão bem acessíveis o que contribuiu muito para o aumento de consumo de embalagens a vácuo. Máquinas nacionais variam de R\$ 5.000,00 a R\$ 350.000,00 dependendo a necessidade do cliente.

Algumas características devem ser observadas na utilização de embalagens a vácuo, como:

- O nível de vácuo aplicado, definirá o teor de oxigênio residual na embalagem em contato com o produto e consequiente alteração de cor, deterioração microbiológica e oxidação de gorduras;

- Taxa de permeabilidade ao oxigênio do material de embalagem, deverá ser baixa, pois a entrada de pequena quantidade de oxigênio na embalagem gera uma baixa pressão parcial deste gás;

- Aderência da embalagem ao produto, desejável para minimizar a exsudação de líquidos, que prejudicam a aparência e favorecem a deterioração microbiológica (KELLER, 2008). 


\subsubsection{Coç̧ão}

O produto pode ser contaminado por microorganismos mesófilos ou por falha na fase de cocção bem como recontaminação. A etapa de cocção é importante para o controle dos microorganismos termosensíveis, bem como o tempo de contato do alimento embalado com a alta temperatura do banho-maria (acima de $70^{\circ} \mathrm{C}$ ).

\subsubsection{Pasteurização}

É a fase essencial para definir a qualidade sensorial, segurança microbiológica, e validade dos produtos. A pasteurização é o procedimento de combinação do binômio tempo/temperatura que deve levar em consideração a curva de sobrevivência dos microorganismos que podem estar presentes na matéria-prima. É indicado que o centro do alimento atinja temperatura de $54,4^{\circ} \mathrm{C}$ dentro de um intervalo de tempo de 6 horas para evitar a produção de toxinas, por exemplo: Clostridium perfringens multiplicando e produzindo toxinas em níveis perigosos (BALDWIN, 2008).

O método de pasteurização destrói por completo a microbiota psicotrófica, entretanto, as enzimas termoestáveis produzidas por estes microorganismos podem sobreviver, promovendo alteração de sabor, ranço e amargor durante o armazenamento do alimento (SILVA JUNIOR, 2007).

\subsubsection{Resfriamento}

Resfriamento é a etapa onde os alimentos são armazenados à temperatura entre $0^{\circ} \mathrm{C}$ e $10^{\circ} \mathrm{C}$, segundo especificações técnicas presentes nos rótulos dos mais variados produtos alimentícios, variando de acordo com seu processamento e natureza microbiológica. Produtos cárneos de bovinos, suínos, aves e outros produtos crus ou que sofreu cocção devem ser armazenados com temperatura máxima de $4^{\circ} \mathrm{C}$ por 72 horas (SILVA JUNIOR, 2007, p. 182).

A etapa de resfriamento do alimento permite que seja feito domínio da multiplicação de microorganismos, o fator determinante para sua eficácia é o controle do binômio tempo / temperatura, ou seja, quanto tempo o alimento leva para atingir uma temperatura de resfriamento técnica, específica e segura. Para esse controle é fundamental a marcação do horário que o alimento foi colocado para refrigerar, levando-se em consideração o tempo necessário para atingir a temperatura segura de $21^{\circ} \mathrm{C}$ em duas horas seguindo para 
$4^{\circ} \mathrm{C}$ em até seis horas, caso seja necessário um resfriamento forçado, alternativas como: imersão em gelo, freezer, geladeira ou equipamento para refrigeração rápida pode ser utilizado (SILVA JUNIOR, 2007).

Microorganismos patogênicos, em sua maioria, chegam ao ápice de proliferação em temperaturas entre $20^{\circ} \mathrm{C}$ a $45^{\circ} \mathrm{C}$, incluindo nesse grupo de agentes os psicrotróficos e os mesófilos, este dado expressa a necessidade de cuidado com o binômio tempo / temperatura, onde o tempo de permanência do alimento nessa faixa de temperatura, deve ser o menor possível. Com maiores riscos tem-se a multiplicação em temperaturas de refrigeração como: Clostridium botulinum a $3^{\circ} \mathrm{C}$, Salmonella sp. a $5,2^{\circ} \mathrm{C}$ e Bacillus cereus a $4^{\circ} \mathrm{C}$ (KAWASAKI, 2007).

\subsubsection{Congelamento}

A etapa de congelamento consiste no armazenamento do alimento a $0^{\circ} \mathrm{C}$ ou temperatura inferior. Fornecedores informam nos rótulos dos alimentos recomendações de validade do produto, onde armazenado de 0 a $-10^{\circ} \mathrm{C}$ o produto vale por 10 dias, -5 a $-10^{\circ} \mathrm{C} \mathrm{o}$ produto vale por 20 dias, de -10 a $-18^{\circ} \mathrm{C}$ o produto terá validade de 30 dias e temperaturas inferiores a $-18^{\circ} \mathrm{C}$ pode-ser armazenar o produto em até 90 dias (SILVA JUNIOR, 2007).

\subsection{SOUS-VIDE SOB O PONTO DE VISTA GASTRONOMICO E NUTRICIONAL}

Os mais renomados Chef's internacionais familiarizados com a técnica de sousvide ressaltam a importância da técnica que conserva o alimento suculento, com cor viva, sabor intenso, estimulando o paladar. Entretanto, outras vantagens são vistas nos alimentos embalados a vácuo, como a proteção que o alimento recebe da exposição ao oxigênio, ausência de contato com microorganismos presentes no ar e preservação de nutrientes durante o processo de cocção (PERLIK, 2006).

A técnica de sous-vide minimiza as perdas hídricas dos alimentos durante a etapa de cozimento, preservando a qualidade sensorial além de estender sua vida útil. Em especial, as carnes tem como prioridade o tratamento térmico, e o cozimento a vácuo permite o alcance das características sensoriais desejadas além de permitir a manutenção do nível nutricional da matéria prima (VAUDAGNA et al., 2002a). 
Por outro lado o valor nutricional de um alimento é determinado pela presença de vários fatores químicos vitais, onde a forma de obtenção é pelo consumo do alimento ou do nutriente via suplementação. Contudo esses nutrientes estão sofrendo alterações a todo o momento, a simples forma de armazenamento dos alimentos pode ocasionar perdas nutricionais bem como a técnica utilizada na preparação para o consumo, onde o calor, a água e baixas temperaturas viabilizam essas perdas (LIGHT, WALKER, 2008).

No conjunto de nutrientes são encontrados macronutrientes (carboidratos, gorduras e proteínas) e micronutrientes (vitaminas e minerais), destes os mais estáveis às alterações são os minerais, porém as gorduras sofrem oxidação e as vitaminas que são compostos orgânicos utilizados pelas células vivas como co-enzimas em reações metabólicas também sofrem alterações e perdas. Essas perdas de vitaminas podem ocorrer de varias formas, entre elas: degradação química durante o processo de cozimento ou se combinado com outros químicos, no caso das hidrossolúveis suas perdas acontecem pela água na cocção, modo de preparo ou armazenamento, degradação por tratamento térmico (vitaminas termosensíveis) e até mesmo pelo contato com a luz, por exemplo, a vitamina C (LIGHT, WALKER, 2008).

Contudo, a técnica de sous-vide, pouco explorada e conhecida no universo gastronômico do restaurante em que trabalho aqui citado fez-se necessário um estudo de caso para entender melhor a técnica afim de conhecer melhor a técnica e evitar possíveis contaminações por manipulação inadequada dos alimentos, assim uma revisão na literatura com identificação dos método tradicional, suas contribuições para a gastronomia elencam os assuntos abordados. 


\section{METODOLOGIA}

A presente pesquisa é um estudo de caso do procedimento realizado com a técnica de sous-vide na preparação de carne bovina em um restaurante flutuante, localizado as margens do Lago Paranoá, na cidade de Brasília - DF.

Foi acompanhado todo o processo de realização da técnica de sous-vide na preparação de carne bovina tipo cupim do restaurante flutuante nos dias 30 de outubro e 01 de novembro de 2008, data e amostra escolhidas por conveniência. O acompanhamento recebeu suporte fotográfico, bem como aferição de temperatura com termômetro de espeto em aço inox (Incoterm ${ }^{\circledR}$ com escala de $-50^{\circ} \mathrm{C} \mathrm{a}+300^{\circ} \mathrm{C}$ ), todos os dados coletados estão descritos na ficha técnica da preparação (APÊNDICE A).

Para a realização da técnica foram utilizados equipamentos específicos como: banho-maria (Maçom ${ }^{\circledR}$, modelo BME9-90) balança (Filizola ${ }^{\circledR}$ modelo MF6), tambler (Lyco® Vaccum Tumbler com capacidade de 40lb), bomba de vácuo (Dosivac ${ }^{\circledR}$ modelo DVR 140), máquina de embalar a vácuo (Selovac $®$ modelo 200B), resfriador rápido para 6 cubas (Fabrinox $\left.{ }^{\circledR}\right)$ e freezer (Consul® modelo CHB42C). Além de embalagem para vácuo (Nylon Poli Protervac ${ }^{\circledR}$ modelo 1010) e marcador permanente de cor preta tipo industrial (Sanford®). 


\section{RESULTADOS E DISCUSSÃO}

O procedimento acompanhado retrata todos os passos da técnica de sous-vide, levando em consideração o pré-preparo, o processo de embalagem, a cocção e o armazenamento, formalizados na ficha técnica da preparação (APENDICE A), sendo respeitado os limites do binômio tempo/temperatura imprescindíveis no controle de qualidade do ponto de vista microbiológico e sensorial do alimento.

O fluxograma (FIGURA 2) a seguir ilustra a técnica de sous-vide realizada no restaurante flutuante, com a utilização de carne bovina, sendo que este mesmo fluxograma pode sofrer alteração de tempo, temperatura e equipamento utilizado de acordo com a matéria prima a ser trabalhada.

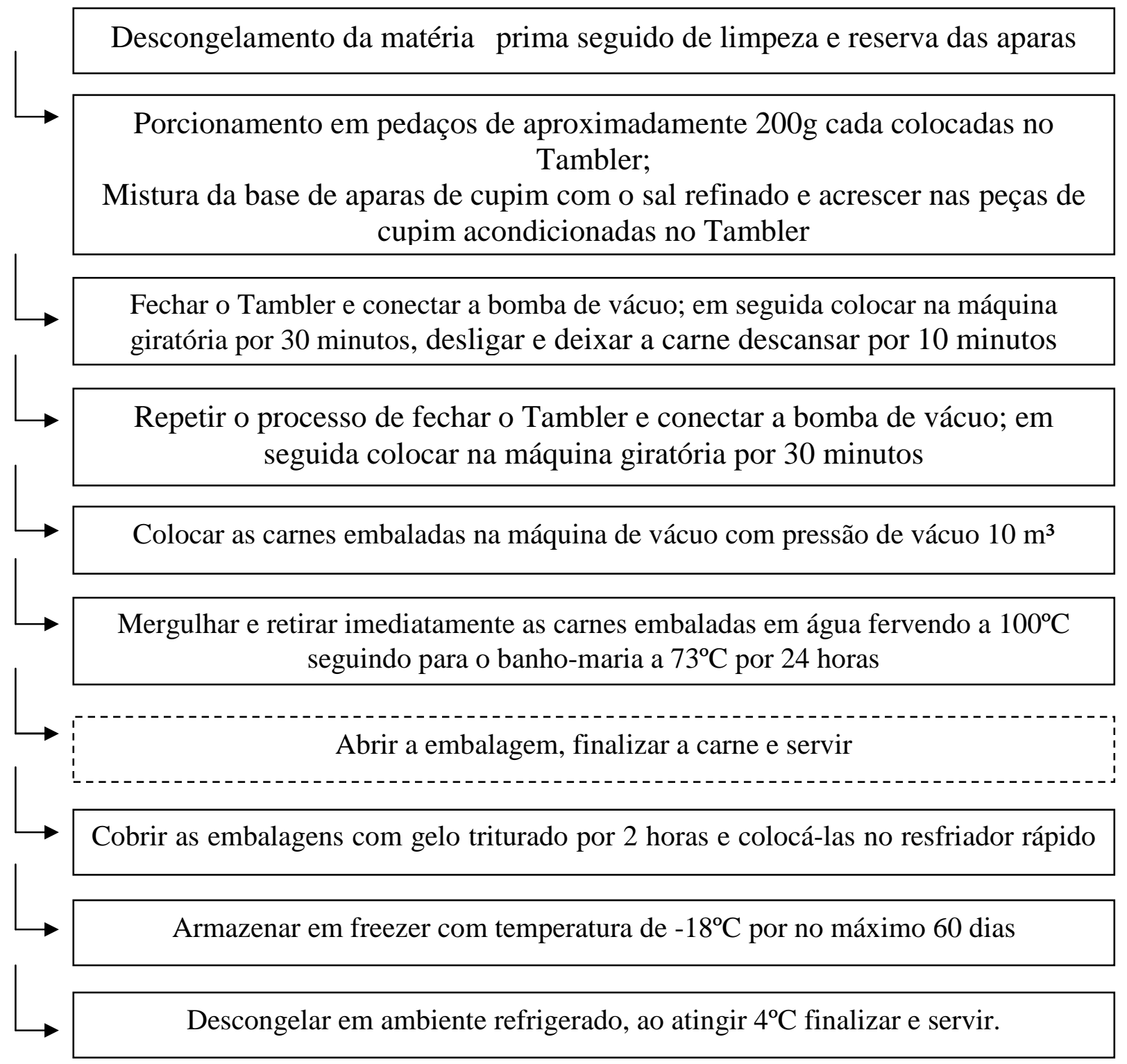

Fig. 2. Fluxograma da técnica de sous-vide realizada no restaurante flutuante 
Particularidades e inovações existem, assim como no flutuante, que utiliza o tambler (FIGURA 3) para auxiliar na maciez da carne, pois este equipamento provoca o relaxamento das fibras da carne promovendo um amaciamento superior ao esperado de uma mesma carne que não passou por esta etapa.
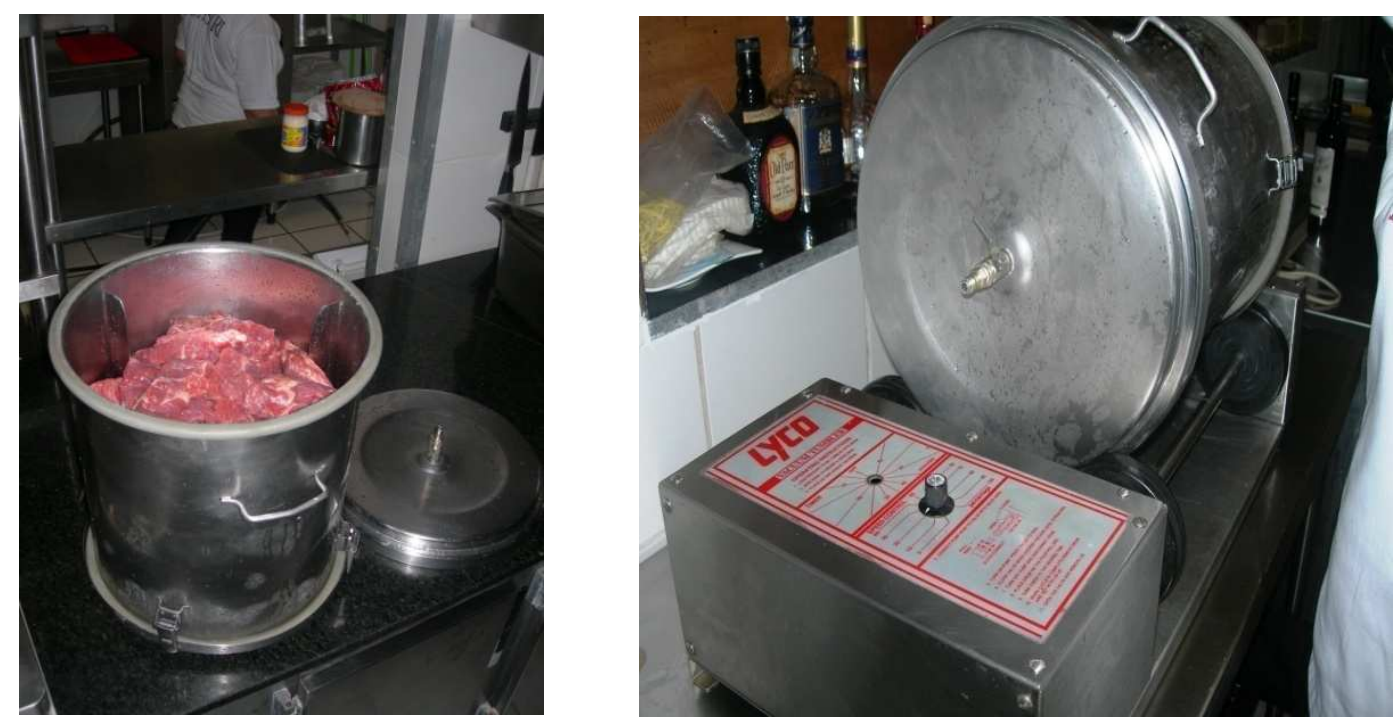

Fig. 3. Utilização do tambler na técnica de sous-vide

Pode-se observar, com o acompanhamento do estudo, que a tecnologia da técnica de sous-vide permite ser utilizada não somente em carnes mas também em vegetais e além da utilização de diferentes cortes, temperos e combinações gastronômicas, preservando suas propriedades nutricionais e sensoriais.

Analisar possíveis erros de manipulação foi um dos objetivos deste estudo, e verificou-se durante o acompanhamento da técnica o hábito errôneo dos manipuladores de alimentos em lavar apenas a palma das mãos e somente com água, não utilizando dos dispositivos como sabonete bactericida e papel toalha descartável que estavam a disposição dos mesmo.

Outro erro de manipulação verificado foi, a não utilização do pedal da lixeira, sendo aberta a tampa pelo manipulador com a mão, sem a correta higienização das mãos posteriormente a este ato (FIGURA 4). Demais erros foram constatados, como banho de gelo em caixa térmica em contato direto com o chão (FIGURA 5), bem como mistura da carne com a base de aparas realizado com as mãos e ante-braço sem proteção, como um mangote (FIGURA 6), porcionamento inicial da matéria prima em um ambiente climatizado fora do restaurante flutuante e transporte dessa matéria prima já porcionada em cubas de inox 
protegidas com tampa sem controle de temperatura. Estes erros podem comprometer a qualidade microbiológica do produto final, sendo as mãos um importante veículo de contaminação, se não realizado sua correta higienização.

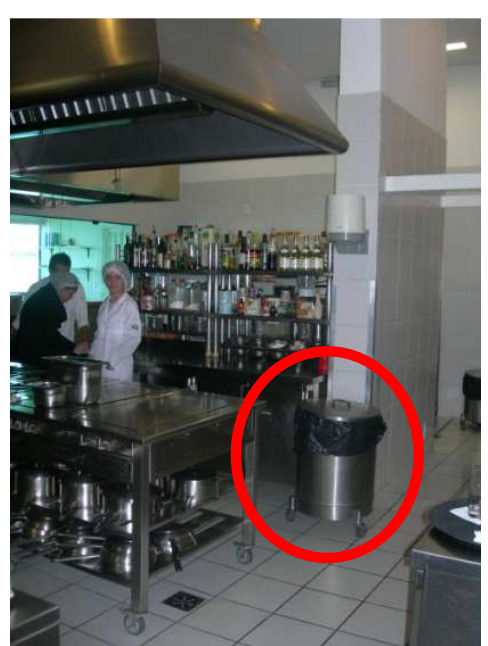

Fig. 4. Lixeira com tampa sem acionamento por pedal

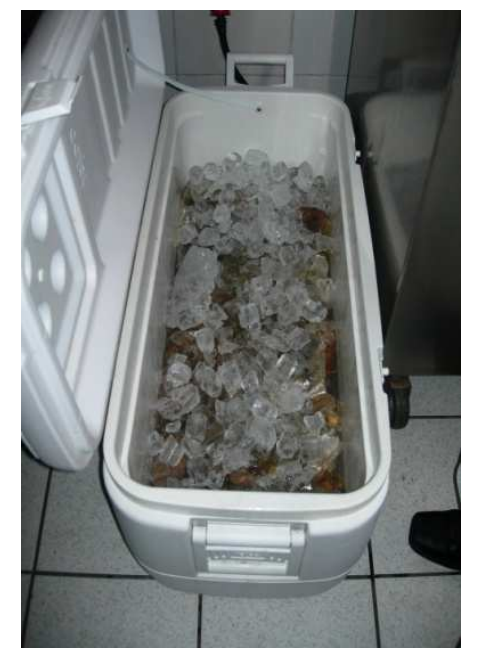

Fig. 5. Banho de gelo em caixa térmica

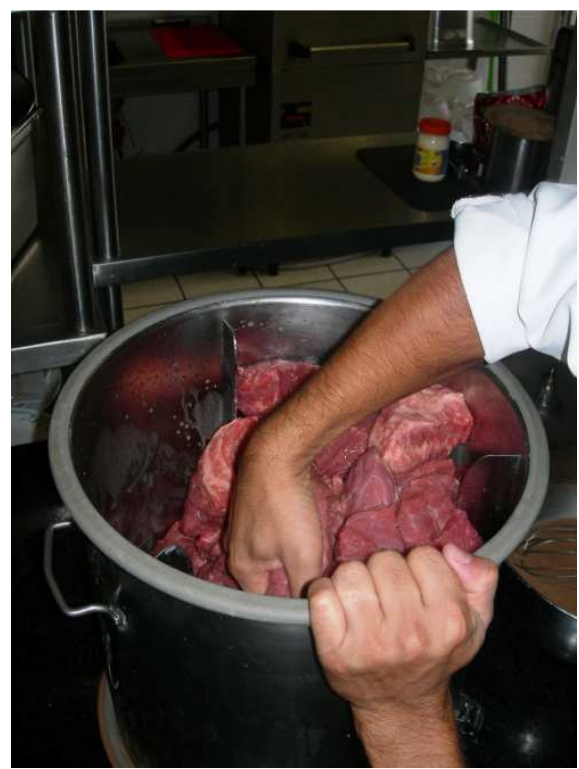

Fig. 6. Mistura da carne com a base de aparas

Os resultados devem ser analisados com ponderação, por ser um estudo de caso, bem como pela falta de recursos para análises laboratoriais microbiológicas dos alimentos e superfícies, além de análises de valores nutricionais do alimento submetido a técnica realizada. 
Entretanto, é válido ressaltar a necessidade de um profissional capacitado para realização da técnica, não só do ponto de vista gastronômico mas também higiênico sanitário, pois a técnica de sous-vide exige um ambiente livre de contaminações com o sistema HACCP implantando e sendo seguido a todo instante por todos que fazem parte da equipe que realiza a técnica.

Além das boas práticas de fabricação, os equipamentos, móveis e utensílios também fazem parte do sistema integrado de segurança para a realização da técnica de embalar a vácuo, uma vez que o vácuo não foi suficiente, ou a embalagem se rompe, se o termômetro não estiver calibrado para aferição e controle da temperatura, ou o sistema de renovação do ar estiver com problemas, riscos de contaminação tornam o alimento impróprio para o consumo.

A revisão de literatura mostra as vantagens nutricionais da técnica de embalar um alimento a vácuo, por seu poder de preservar os nutrientes presentes na matéria prima, devese levar em consideração que preparações calóricas, ricas em gorduras, carboidratos e proteínas terão suas propriedades também preservadas, devendo ser consumidas com cautela principalmente por aqueles indivíduos com restrições calóricas ou de algum nutriente específico que não se desnaturou durante o procedimento do preparo.

A preparação estudada, preparo de cupim na técnica de sous-vide, é rica em gordura devido a peça de carne utilizada, não recomendada para pessoas portadoras de hipertensão, diabetes, colesterol alto, trigliceridemia, hipercolesterolemia, entre outros que pode vir a agravar o quadro patológico do indivíduo. Em contrapartida, outros alimentos podem e devem ser consumidos por estarem com suas vitaminas e minerais preservados pela técnica de sous-vide como os vegetais que são fontes desses nutrientes e auxiliam na prevenção e no tratamento de diversas doenças. 


\section{CONCLUSÃO}

A técnica de sous-vide foi estudada para compreender os procedimentos realizados no restaurante flutuante. Durante a coleta de informações verificou-se a amplitude da técnica, suas vantagens e suas desvantagens, e por que não utilizar o termo exigências, pois a técnica permite inovações, tecnologias alternativas e diferentes métodos de preparação para os mais diversos tipos de alimentos. Ao se falar em exigências torna-se claro a preocupação com o conjunto de ações que tem como objetivo as boas práticas de manipulação, utilização do sistema APPCC e o controle real do binômio tempo/temperatura para um produto final seguro e de qualidade, além do valor nutricional natural da matéria prima que é preservado durante as etapas da técnica.

A verificação de erros de boas práticas de manipulação instigou a necessidade de treinamento dos manipuladores, o qual foi realizado em dezembro de 2008 com apoio de material didático, filme, data show e dinâmicas de lavagem das mãos. Além disso, foi proposto campanha educativa mensal, reciclagem de boas práticas a cada seis meses, com treinamentos teórico e prático, afim de minimizar os riscos de contaminação controlando este ponto crítico e profissionalização da equipe.

Por fim, conclui-se que apesar de ser uma técnica da década de 60, ainda está sendo conhecida e explorada e que necessita de mais pesquisas e trabalhos que realizem testes laboratoriais que validem a segurança e as vantagens nutricionais da técnica. Outros estudos de caso e estudos comparativos seriam de grande valia para a compreensão e utilização segura da técnica de sous-vide. 


\section{REFERÊNCIAS}

BALDWIN, D. E. A pratical guide to sous vide cooking. 2008.

CAMPOS, S. Entrevista com Georges Pralus. Entrevista concedida a Florence Rayal. Disponível em: < http://www.drashirleydecampos.com.br/noticias/5017 >. Acesso em: 30 nov 2008.

FARBER, J. M.; DODDS, K. L. Principles of modified-atmosphere and sous vide product packaging. Lancaster: Technomic, pp. 37, 142, 211, 212, 219, 222, 226, 255-256, 261, 1995. Disponível em: <http://books.google.com.br/books?id=CWkH8YHiYsEC\&pg=PA255\&lpg= PA255\&dq=nacka+e+AGS\&source=bl\&ots=EjbRLUlbix \&sig=3ZZQVjqAUMzce45i8Akgd vR8ag\&hl=pt-BR\&sa=X\&oi=book_result\&resnum=6\&ct=result\#PPP1,M1> Acesso em: 30 nov 2008.

GARCÍA-LINARES, M.C.; GONZALEZ-FANDOS, E.; GARCÍA-FERNÁNDEZ, M.C.; GARCÍA-ARIAS, M.T. Microbiological and nutritional quality of sous vide or traditionally processed fish: influence of fat content. Journal of Food Quality, v.27, p.371-387, 2004.

KAWASAKI, V. M. Sistema Cook-chill para o Controle de Alimentos In: SILVA JUNIOR, E. A. Manual de Controle Higiênico-Sanitário em Serviços de Alimentação. São Paulo: Livraria Varela, cap.6, pp.410-416, 2007.

KELLER, T., Under Pressure - cooking sous vide. Singapore: Artisan, Divisão da Workman Publishing Company, Inc, pp. 2-8, 23-35, 2008.

KINTON, R.; CESERANI, V.; FOSKETT, D. Enciclopédia de serviços de alimentação. São Paulo: Livraria Varela, p. 703, 1998.

LIGHT, N.D., WALKER, A. Cook-Chill Catering: technology and management. London: Elsevier Applied Science, pp. 35, 36, 140-150, 1990. Disponível em: < http://books.google.com.br/books?id=aFgpFQYQ3tgC\&pg=PT371\&lpg=PT371\&dq=ags+ho spital+sous+vide\&source=bl\&ots=SaIEIClrg7\&sig=DAFgse7nfErQE4QsjCw2WjCyQ8\&hl= pt-BR\&sa=X\&oi=book_ result\&resnum=4\&ct=result\#PPP1,M1>. Acesso em: 30 nov de 2008.

LIMA, D.M. et al. Tabela Brasileira de Composição de Alimentos - TACO. Campinas, São Paulo: NEPA / UNICAMP. $2^{\mathrm{a}}$ ed.,2006.

ORGANIZAÇÃO MUNDIAL DA SAÚDE. Food safety and food borne illness. Disponível em: http://www.who.int/inf-fs/en/fact237.html. Acesso em: 15 set. de 2008.

PANETTA, J.C. Saneamento básico e segurança dos alimentos. Rev. Hig. Alim., Sâo Paulo, v.15, n.88, p.3, 2001.

PERLIK, A. Seal of approval: as America's top chefs welcome sous-vide cooking to their kitchens, they make safety the top priority and intense flavor a goal. Chicago Sun-Times, Chicago, 15 de abril de 2006. Disponível em: http://www.encyclopodia.com/doc/1039sousvide.html. Acesso em: 15 set de 2008. 
RESENDE, R.V. Brasil: a case study. Food Policy, Oxford, v.18, p.120-130, 1993.

SHELDON MARGEN, M.D.; OGAR D.A. Vacuum process packs in flavor in convenience foods. Chicago Sun-Times, Chicago, 11 de setembro de 1989. Disponível em: http://www.encyclopodia.com/doc/1039-sousvide.html. Acesso em: 15 set de 2008.

SILVA JUNIOR, E. A. Manual de Controle Higiênico-Sanitário em Serviços de Alimentação. São Paulo: Livraria Varela, pp.21-42, 182, 2007.

TANSEY, F.S.; GORMLEY, T.R. Sous Vide / Freezing Techology for Ready Meals In: BARBOSA-CÁNOVAS, Gustavo V.; TAPIA, María S.; CANO, M. Pilar. Novel Food Processing Technologies. Routledge, USA, cap. 22, pp. 477-478, 2004. Disponível em: $<$ http://books.google.com.br/books?id=fpZVpf17JkC\&printsec=frontcover\&dq=Novel+Food +Processing+Technologies\&lr=\#PPP1,M> Acesso em: 27 nov de 2008.

VAUDAGNA, S.R.; SANCHEZ, G.; MASANA, M. O.; PICALLO, M. B.; NEIRA, M. S.; LASTA, J. A. Cocción Sous Vide con tratamientos térmicos baja temperatura: Nuevas Herramientas Para El Procesamiento De Cortes De Carne Bovina. Revista IDIA XXI. Ediciones Instituto Nacional de Tecnología Agropecuaria. Año II - n. 2 p.163-168, 2002a.

VAUDAGNA, S. R.; SANCHEZ, G.; NEIRA, M. S.; INSANI, E.M.; PICALLO, A.B.; GALLINGER, M. M.; LASTA, J. A. Sous Vide Cooked Beef Muscles: Effect of Low Temperature-Long Time (Lt-Lt) Treatments on Their Quality Characteristics and Storage Stability. International Journal of Food Science and Technology, v.37, p.425-441, 2002b.

VYNCKT, V. V. Processed foods find flavor in sous vide. Chicago Sun-Times, Chicago, 21 de janeiro de 1990. Disponível em: http://www.encyclopodia.com/doc/1039-sousvide.html. Acesso em: 15 set de 2008. 


\section{APÊNDICE A - FICHA TÉCNICA PRÉ PREPARO DE CUPIM}

Nome da Preparação: Pré preparo de cupim na técnica de sous vide

Entrada ( ) Prato principal (x ) Guarnição ( ) Molho ( ) Sobremesa ( )

Data: 30 de novembro de 2008.

\begin{tabular}{|l|r|r|r|}
\hline \multicolumn{1}{|c|}{ ALIMENTO } & \multicolumn{1}{c|}{$\begin{array}{c}\text { PB }(\mathrm{Kg} / \mathrm{L}) \\
\text { Total }\end{array}$} & $\begin{array}{c}\text { PL(Kg/L) } \\
\text { Total }\end{array}$ & \multicolumn{1}{c|}{ FC } \\
\hline Cupim congelado & 26.656 & 21.325 & 1.25 \\
\hline Base de aparas de cupim & 1.280 & 1.280 & 1.00 \\
\hline Sal refinado & 0.227 & 0.227 & 1.00 \\
\hline
\end{tabular}

Técnica de preparo:

1. Colocar as peças de cupim para descogelar em ambiente refrigerado a aproximadamente $4.5^{\circ} \mathrm{C}$ por 24 horas.

2. Em ambiente climatizado a $\pm 14^{\circ} \mathrm{C}$ abrir as embalagens das peças de cupim, e limpar a carne retirando o excesso de gordura, reservar as aparas para preparação da base de aparas de cupim.

3. Porcionar as peças de cupim em pedaços de aproximadamente $200 \mathrm{~g}$ cada

4. Em uma cuba de inox misturar a base de aparas de cupim com o sal refinado.

5. Colocar as peças de cupim limpas no Tambler e acrescentar a base acrescida de sal.

6. Fechar o Tambler e conectar a bomba de vácuo.

7. Colocar na máquina giratória por 30 minutos.

8. Retirar o vácuo, deixar a carne descansar por 10 minutos em ambiente refrigerado a aproximadamente $4.5^{\circ} \mathrm{C}$.

9. Repetir os passos 6; 7 e 8 .

10. Colocar as peças em embalagens para armazenamento a vácuo identificadas com o nome do alimento, data de fabricação e data de validade.

11. Colocar as carnes embaladas na máquina de vácuo com pressão de vácuo 10 e solda 05 .

12. Moldar as peças de carne embaladas.

13. Mergulhar as carnes embaladas por aproximadamente 5 segundos em água fervendo a $100^{\circ} \mathrm{C}$

14. Colocar as carnes embaladas em banho-maria a $73^{\circ} \mathrm{C}$ por 24 horas, e cobri-las com gelo triturado por 2 horas.

15. Retirar as carnes embaladas do gelo, secar e colocar no resfriador rápido a $6^{\circ} \mathrm{C}$ durante 12 horas.

16. Retirar as carnes embaladas e armazenar em freezer com temperatura de $-18^{\circ} \mathrm{C}$. 


\section{ANÁLISE PER CAPITA}

Preparação: Pré preparo de cupim na técnica de sous vide

\section{Peso Total da Porção: $210 \mathrm{~g}$}

\begin{tabular}{|c|c|c|c|c|c|c|c|c|c|c|c|c|c|c|c|c|c|c|c|c|c|}
\hline Alimento & $\begin{array}{l}\text { Quant. } \\
(\mathrm{g} / \mathrm{ml})\end{array}$ & $\begin{array}{c}\text { Cal } \\
\text { (Kcal) }\end{array}$ & $\begin{array}{l}\text { Glíc } \\
(\mathrm{g})\end{array}$ & $\begin{array}{c}\text { PTN } \\
(\mathrm{g})\end{array}$ & $\begin{array}{l}\text { Lip } \\
(\mathrm{g})\end{array}$ & $\begin{array}{c}\text { Col } \\
(\mathrm{mg})\end{array}$ & $\begin{array}{l}\text { Sat } \\
(\mathrm{g})\end{array}$ & $\begin{array}{c}\text { Mon } \\
\text { (g) }\end{array}$ & $\begin{array}{l}\text { Pol } \\
\text { (g) }\end{array}$ & $\begin{array}{c}\mathrm{Ca} \\
(\mathrm{mg})\end{array}$ & $\begin{array}{c}\mathrm{P} \\
(\mathrm{mg})\end{array}$ & $\begin{array}{c}\mathrm{Fe} \\
(\mathrm{mg})\end{array}$ & $\begin{array}{l}\mathrm{Na} \\
(\mathrm{mg})\end{array}$ & $\begin{array}{c}\mathrm{K} \\
(\mathrm{mg})\end{array}$ & $\begin{array}{c}\mathrm{Zn} \\
(\mathrm{mcg})\end{array}$ & $\begin{array}{c}\text { Tia } \\
(\mathrm{mcg})\end{array}$ & $\begin{array}{l}\text { Niac } \\
(\mathrm{mg})\end{array}$ & $\begin{array}{l}\text { Rib. } \\
\text { (mcg) }\end{array}$ & $\begin{array}{c}\text { A } \\
(\mathrm{mcg})\end{array}$ & $\begin{array}{c}\mathrm{C} \\
(\mathrm{mg})\end{array}$ & $\begin{array}{l}\text { Fibr } \\
(\mathrm{g})\end{array}$ \\
\hline Cupim & 200 & 442 & 0 & 39 & 30,6 & 102 & 13,6 & 12,8 & 0,4 & 8 & 440 & 2,2 & 94 & 302 & 4,8 & 0,22 & 6,66 & 0,1 & 6 & & NA \\
\hline $\begin{array}{l}\text { Base de } \\
\text { aparas de } \\
\text { cupim }\end{array}$ & 13 & & 80,04 & 15,48 & 2,22 & 2,62 & 0,35 & 0,33 & 0,01 & 177,8 & 330 & 1,99 & 21,50 & 1756 & 3,43 & 0,33 & 0,17 & 0,16 & 0,00 & 47,1 & 25,9 \\
\hline $\begin{array}{l}\text { Sal } \\
\text { refinado }\end{array}$ & 2 & & & & & & & & & & NA & NA & 798,86 & NA & NA & NA & NA & NA & NA & & NA \\
\hline
\end{tabular}

\begin{tabular}{|c|c|c|c|c|c|c|c|c|c|c|c|c|c|c|c|c|c|c|c|c|}
\hline TOTAL & 215 & 80,04 & 54,5 & 32,8 & 105 & 14 & 13 & 0,41 & 186 & 770 & 4,2 & 914,4 & 2058 & 8,23 & 0,55 & 6,83 & 0,26 & 6 & 47,1 & 25,9 \\
\hline & & x 4 & x 4 & x 9 & & & & & & & & & & & & & & & & \\
\hline & & 322 & 218 & 295 & & & & & & & & & & & & & & & & \\
\hline
\end{tabular}

Caloria total da preparação: $835 \mathrm{Kcal}$ 


\section{APÊNDICE B - FICHA TÉCNICA DA BASE BASE DE APARAS DE CUPIM}

Nome da Preparação: Base de aparas de cupim

Entrada ( ) Prato principal ( ) Guarnição ( ) Molho (x ) Sobremesa ( )

Data: 30 de novembro de 2008.

\begin{tabular}{|l|r|r|r|}
\hline \multicolumn{1}{|c|}{ ALIMENTO } & \multicolumn{1}{c|}{$\begin{array}{c}\text { PB }(\mathrm{Kg} / \mathrm{L}) \\
\text { Total }\end{array}$} & $\begin{array}{c}\text { PL(Kg/L) } \\
\text { Total }\end{array}$ & \multicolumn{1}{c|}{ FC } \\
\hline Aparas de cupim & 5.331 & 5.331 & 1.00 \\
\hline Salsão & 0.137 & 0.106 & 1.29 \\
\hline Alho poro & 0.122 & 0.106 & 1.15 \\
\hline Cebola & 0.530 & 0.490 & 1.08 \\
\hline Cenoura & 0.530 & 0.473 & 1.12 \\
\hline
\end{tabular}

Técnica de preparo:

1. Realizar a higienização dos vegetais, seguido da retirada das partes não comestíveis ou impróprias para consumo.

2. Cortar os vegetais em cortes irregulares "mirepoix".

3. Em uma panela funda de aproximadamente 15 litros, coloque o salsão, alho poro, cebola e a cenoura, mexa por aproximadamente 2 minutos, acrescente as aparas de cupim e continue mexendo por mais 3 minutos.

4. Acrescente a água fria, tampe a panela e deixe cozinhar em fogo baixo por 8 horas.

5. Apague o fogo e coe com auxilio do "chinois", despejando em outra panela cuja base esteja sobre uma forma com gelo para um choque térmico.

6. Utilizar em seguida na preparação desejada ou porcionar em embalagens plásticas descartáveis com tampa identificadas com nome da preparação data de fabricação e validade e armazenar em freezer com temperatura de $-18^{\circ} \mathrm{C}$. 


\section{ANÁLISE PER CAPITA}

Preparação: Base de aparas de cupim

Peso Total da Porção: 13ml

\begin{tabular}{|c|c|c|c|c|c|c|c|c|c|c|c|c|c|c|c|c|c|c|c|c|c|}
\hline Alimento & $\begin{array}{l}\text { Quant. } \\
\text { (g/ml) }\end{array}$ & $\begin{array}{c}\mathrm{Cal} \\
(\mathrm{Kcal})\end{array}$ & $\begin{array}{l}\text { Glíc } \\
\text { (g) }\end{array}$ & $\begin{array}{l}\text { PTN } \\
(\mathrm{g})\end{array}$ & $\begin{array}{l}\operatorname{Lip} \\
(\mathrm{g})\end{array}$ & $\begin{array}{c}\text { Col } \\
(\mathrm{mg})\end{array}$ & $\begin{array}{l}\text { Sat } \\
(g)\end{array}$ & $\begin{array}{c}\text { Mon } \\
(\mathrm{g})\end{array}$ & $\begin{array}{l}\text { Pol } \\
(\mathrm{g})\end{array}$ & $\begin{array}{c}\mathrm{Ca} \\
(\mathrm{mg})\end{array}$ & $\begin{array}{c}\mathrm{P} \\
(\mathrm{mg})\end{array}$ & \begin{tabular}{|c|}
$\mathrm{Fe}$ \\
$(\mathrm{mg})$
\end{tabular} & $\begin{array}{l}\mathrm{Na} \\
(\mathrm{mg})\end{array}$ & \begin{tabular}{c|}
$\mathrm{K}$ \\
$(\mathrm{mg})$
\end{tabular} & $\begin{array}{c}\mathrm{Zn} \\
(\mathrm{mcg})\end{array}$ & $\begin{array}{c}\mathrm{Tia} \\
(\mathrm{mcg})\end{array}$ & $\begin{array}{l}\text { Niac } \\
(\mathrm{mg})\end{array}$ & $\begin{array}{l}\text { Rib. } \\
\text { (mcg) }\end{array}$ & $\begin{array}{c}\mathrm{A} \\
(\mathrm{mcg})\end{array}$ & \begin{tabular}{|c|}
$\mathrm{C}$ \\
$(\mathrm{mg})$
\end{tabular} & $\begin{array}{c}\text { Fibr } \\
(\mathrm{g})\end{array}$ \\
\hline $\begin{array}{l}\text { Aparas de } \\
\text { cupim }\end{array}$ & 5,13 & 11,34 & 0,00 & 1,00 & 0,79 & 2,62 & 0,35 & 0,33 & 0,01 & 0,21 & 11,3 & 0,06 & 2,41 & 7,75 & 0,12 & 0,01 & 0,17 & 0,00 & 0,00 & & NA \\
\hline Salsão & 0,10 & 0,03 & 0,01 & 0,00 & 0,00 & NA & & & & 0,18 & 0,05 & 0,00 & 0,00 & 753,7 & 1,38 & 0,13 & & 0,16 & NA & & 0,00 \\
\hline Alho poro & 0,10 & & & & & & & & & & & & & & & & & & & & \\
\hline Cebola & 0,47 & 0,18 & 43,61 & 8,33 & 0,49 & NA & & & & 68,6 & 186,2 & 0,98 & 4,90 & 862,4 & 0,98 & 0,20 & & & & 23,0 & 10,8 \\
\hline Cenoura & 0,46 & 160,82 & 36,42 & 6,15 & 0,95 & NA & & & & 108,8 & 132,4 & 0,95 & 14,19 & 132,4 & 0,95 & & & & NA & 24,1 & 15,1 \\
\hline
\end{tabular}

\begin{tabular}{|c|c|c|c|c|c|c|c|c|c|c|c|c|c|c|c|c|c|c|c|c|}
\hline Total & 13 & 80,04 & 15,48 & 2,22 & 2,62 & 0,35 & 0,33 & 0,01 & 177,8 & 330 & 1,99 & 21,50 & 1756 & 3,43 & 0,33 & 0,17 & 0,16 & 0,00 & 47,1 & 25,9 \\
\hline & & x 4 & x 4 & × 9 & & & & & & & & & & & & & & & & \\
\hline & & 320,1 & 61,9 & 20,0 & & & & & & & & & & & & & & & & \\
\hline
\end{tabular}

Caloria total da preparação: $402 \mathrm{Kcal}$ 